\title{
Zeolite Y Films as Ideal Platform for Evaluation of Third-Order Nonlinear Optical Quantum Dots
}

\author{
Hyun Sung Kim \\ Department of Chemistry, Pukyong National University, Busan 48513, Republic of Korea \\ Correspondence should be addressed to Hyun Sung Kim; kimhs75@pknu.ac.kr
}

Received 19 February 2016; Accepted 5 May 2016

Academic Editor: Bo Tan

Copyright (C) 2016 Hyun Sung Kim. This is an open access article distributed under the Creative Commons Attribution License, which permits unrestricted use, distribution, and reproduction in any medium, provided the original work is properly cited.

\begin{abstract}
Zeolites are ideal host material for generation and stabilization of regular ultrasmall quantum dots (QDs) array with the size below $1.5 \mathrm{~nm}$. Quantum dots (QDs) with high density and extinction absorption coefficient have been expected to give high level of third-order nonlinear optical (3rd-NLO) and to have great potential applications in optoelectronics. In this paper, we carried out a systematic elucidation of the third-order nonlinear optical response of various types of QDs including PbSe, $\mathrm{PbS}, \mathrm{CdSe}, \mathrm{CdS}, \mathrm{ZnSe}$, $\mathrm{ZnS}, \mathrm{Ag}_{2} \mathrm{Se}$, and $\mathrm{Ag}_{2} \mathrm{~S}$ by manipulation of QDs into zeolites Y pores. In this respect, we could demonstrate that the zeolite offers an ideal platform for capability comparison 3rd-NLO response of various types of QDs with high sensitivities.
\end{abstract}

\section{Introduction}

Materials with large and fast nonlinear responses are highly essential for practical optical devices, owing to the high thirdorder nonlinear optical (denoted as 3rd-NLO) responses of the NLO materials [1]. These properties endorse them as promising candidate materials for all-optical switches [2] and waveguides [3], which are key components in high-speed alloptical telecommunication [4] and optical limiters [5], as well as high-performance saturable absorbers [6] in mode-locked laser system. Therefore, there has been considerable interest lately in the development of new materials with higher 3rdNLO response.

Meanwhile, semiconductor quantum dots (QDs) dispersed in host matrices, such as polymer [7], glass dielectric [8], and others [9-11], have been extensively investigated as promising candidate materials with very high $3 \mathrm{rd}-\mathrm{NLO}$ responses. This could be attributed to not only their quantum size effects but also their interface and surface structure. Some representative QDs include PbS [12], PbSe [13], CdS [14], CdSe [15], CdTe [16], ZnS [17], ZnSe [18], ZnTe [19], $\mathrm{In}_{2} \mathrm{~S}_{3}$ [20], CuS [21], and so forth [22, 23]. However, the 3rdNLO response values that have been reported so far do not meet the simultaneous requirement of large and fast 3rd-NLO responses for being useful in practical applications.
Along this line, it has been proposed that zeoliteintercalated QDs would give very high 3rd-NLO responses $[24,25]$. This speculation is on the basis of the following expectations: the size of the intercalated QDs will be much smaller $(<1.5 \mathrm{~nm})$ than that of the QDs in other matrices; QDs of highly uniform size, when arranged in a periodic way into the zeolite crystalline host, will give rise to increased concentration of QDs per constant matrices volume. For the first time, Kim and Yoon reported the extraordinarily high level of 3rd-NLO responses of zeolite-intercalated $\mathrm{PbS}$ QDs [26]. Thus, the nonlinear refractive $(\gamma)$ and absorption $(\beta)$ coefficients of the zeolite-intercalated PbS QDs, the two important properties of 3rd-NLO materials, are $\sim 20$ to 330 times higher than the highest values obtained from other QD-dielectric matrix systems [12-23] at 532 and $1064 \mathrm{~nm}$, respectively. Moreover, very recently, Lee and Kim [27] demonstrated that the electric field strength, framework donor strength, and cation acceptor strength in zeolites as the QD host could be sensitively and systematically changed via varying cation species in the zeolite framework. This is one of the unique advantages of using zeolites as the hosts for QDs, given the fact that the conventional dielectric matrices cannot easily and systematically change the environment of generated QDs. These results demonstrated that the zeolite could be an ideal host not only for the generation of ultrasmall QDs 
organized into regular arrays but also for facilitating a perfect condition to enhance the 3rd-NLO response by systemically changing the surrounding environment of generated QDs.

\section{Experimental Section}

2.1. Preparation of Zeolite Y Film on ITO Glass. Zeolite Y seed crystals $(80 \mathrm{~nm}, 1 \mathrm{~g})$ were prepared according to the literature procedure [28] and dispersed in DDW (0.1 w\%). Independently, several pieces of ITO glass $(30 \times 30 \mathrm{~mm})$ were cleaned with ultrasound sonication in mucosal solution (3\%) for $10 \mathrm{~min}$ and subsequently washed with copious amounts of water. The aqueous suspension of the seed crystals was spin-coated twice onto the ITO side at the speed of 2,000 rpm. The seeded ITO glasses were then kept for $30 \mathrm{~min}$ in an oven preheated to $100^{\circ} \mathrm{C}$ for adhesion. After cooling to room temperature, the seeded ITO glasses were placed vertically on a Teflon support. The support was then immersed into a synthesis gel with the molar composition of $14 \mathrm{Na}_{2} \mathrm{O}: \mathrm{Al}_{2} \mathrm{O}_{3}: 10 \mathrm{SiO}_{2}: 720 \mathrm{H}_{2} \mathrm{O}$, and the reactor was placed for $12 \mathrm{~h}$ in an oven preheated to $100^{\circ} \mathrm{C}$. The average thickness of the resulting zeolite $\mathrm{Y}$ films was $2.5 \mu \mathrm{m}$.

2.2. Preparation of $M S$ or MSe Quantum Dot $(M=P b, C d$, $\mathrm{Ag}$, and $\mathrm{Zn}$ )-Containing Zeolite Y Films Supported on ITO Glass. Zeolite $\mathrm{Y}$ films (denoted as $\mathrm{Y}_{\mathrm{f}}$ ) were immersed into each $25 \mathrm{~mL}$ aliquot of various types of metal ion source solution $(0.1 \mathrm{mM})$ such as $\mathrm{Cd}\left(\mathrm{NO}_{3}\right)_{2}, \mathrm{~Pb}\left(\mathrm{NO}_{3}\right)_{2}, \mathrm{AgNO}_{3}$, and $\mathrm{Zn}\left(\mathrm{NO}_{3}\right)_{2}$ for $10 \mathrm{~min}$ at room temperature. The desired ionexchanged $\mathrm{Y}_{\mathrm{f}}$ films supported on ITO glass were washed with copious amounts of distilled deionized water and subsequently dried under a stream of $\mathrm{N}_{2}$ and were introduced into a Schlenk tube and dried at $200^{\circ} \mathrm{C}$ for $12 \mathrm{~h}$ under vacuum $(<$ $10^{-5}$ Torr). After cooling to the room temperature, dry $\mathrm{H}_{2} \mathrm{~S}$ gas was introduced into the Schlenk tube, and the tube was kept for $30 \mathrm{~min}$ at the room temperature to generate desired $\mathrm{MS}(\mathrm{M}=\mathrm{Pb}, \mathrm{Cd}, \mathrm{Ag}$, and $\mathrm{Zn})-\mathrm{QD}$ in zeolite $\mathrm{Y}$. The remaining unreacted $\mathrm{H}_{2} \mathrm{~S}$ gas was removed by evacuation. Instead of $\mathrm{H}_{2} \mathrm{~S}$, when dry $\mathrm{H}_{2} \mathrm{Se}$ gas was introduced into the reaction, MSe ( $\mathrm{M}=\mathrm{Pb}, \mathrm{Cd}, \mathrm{Ag}$, and $\mathrm{Zn})$-QDs in zeolite $\mathrm{Y}$ films were obtained.

2.3. Instrumentation. The $\theta-2 \theta$ scans of $\mathrm{Y}_{\mathrm{f}}$ films were performed on a Rigaku Ultima 4 with the power of $40 \mathrm{kV}$ and $40 \mathrm{~mA}$. The wavelength of the monochromated X-ray beam was $1.5406 \mathrm{~nm}$ generated from $\mathrm{Cu} \mathrm{K} \alpha$ radiation. Diffuse reflectance UV-vis spectra of the samples were recorded on a Varian Cary 5000 UV-Vis-NIR spectrophotometer equipped with an integrating sphere. Barium sulfate $\left(\mathrm{BaSO}_{4}\right)$ was used as the reference. The diffuse reflectance spectra were converted into the Kubelka-Munk (K-M) formalism.

Measurement of 3rd-NLO response of various types of quantum dots was conducted according to the literature [25, 26].

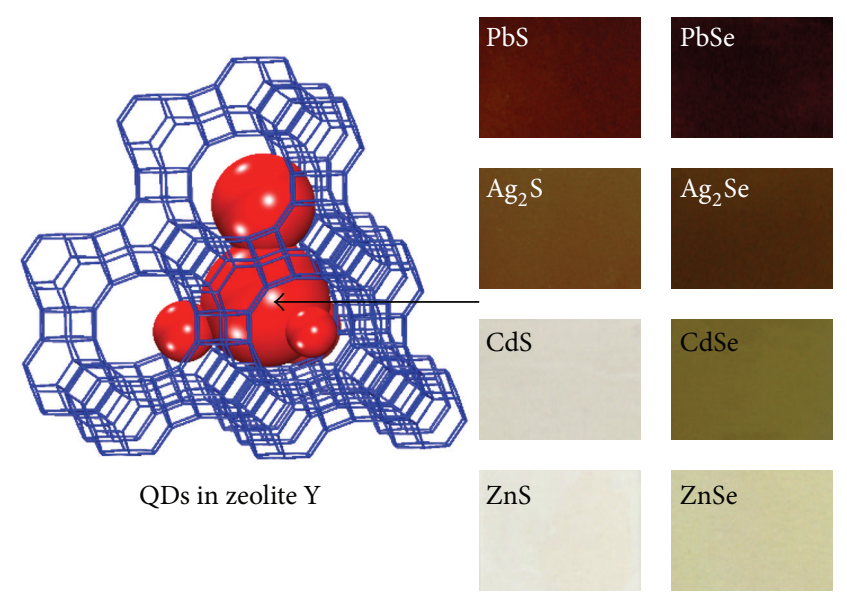

Scheme 1: Schematic representation of QDs encapsulated in zeolite $\mathrm{Y}$ and photograph images of zeolite $\mathrm{Y}$ films containing the QDs.

\section{Results and Discussion}

In general, metal sulphide (MS) or metal selenide (MSe) QDs could be produced inside zeolite Y (in Scheme 1) via the following simple chemical reaction [28]. In the typical process, dried and fully different $\mathrm{M}^{+}$or $\mathrm{M}^{2+}$-exchanged zeolite $\mathrm{Y}$ is treated with dry $\mathrm{H}_{2} \mathrm{~S}$ gas according to

$$
\begin{aligned}
& {\left[\mathrm{M}^{+} \text {or } \mathrm{M}^{2+}\right] \mathrm{Y}+\operatorname{dry} \mathrm{H}_{2} \mathrm{~S}} \\
& \quad \longrightarrow\left[\left(\mathrm{M}_{2} \mathrm{~S} \text { or } \mathrm{MS}\right) \mathrm{QD}, 2 \mathrm{H}^{+}\right] \mathrm{Y}
\end{aligned}
$$

where [ ]Y represents zeolite Y, (PbS)QD represents PbS QDs, and $2 \mathrm{H}^{+}$represent $2 \mathrm{H}^{+}$ions charge-balancing two negative $\mathrm{Al}$ centres in zeolite $\mathrm{Y}$ framework instead of $\mathrm{P}^{2+}$ ion.

Zeolite, as the host for QDs, offers an opportunity to compare the 3rd-NLO responses of various MS or MSe QDs under identical conditions, especially in terms of the volume fraction of QDs relative to matrices, size, and matrix environment. In the present study, we prepared various metal chalcogenide QDs such as PbSe, PbS, CdSe, CdS, ZnSe, ZnS, $\mathrm{Ag}_{2} \mathrm{Se}$, and $\mathrm{Ag}_{2} \mathrm{~S}$ intercalated into zeolite Y. To the best of our knowledge, for the first time in this study, we evaluated and compared 3rd-NLO responses of various types of QDs at different wavelengths, namely, $532 \mathrm{~nm}$ and $1065 \mathrm{~nm}$, under exactly constant circumstances.

Zeolite $\mathrm{Y}$ films (denoted as $\mathrm{Y}_{\mathrm{f}}$ ) grown on the indium-tinoxide-coated glass plates were used in this study. This was particularly chosen because the films remain firmly bonded to the substrates even during subsequent chemical treatments, such as fully ion exchange with various heavy metal cations including $\mathrm{Pb}^{2+}, \mathrm{Cd}^{2+}, \mathrm{Zn}^{2+}$, and $\mathrm{Ag}^{+}$ions, drying, and formation of metal chalcogenides MS and MSe via treatment with $\mathrm{H}_{2} \mathrm{~S}$ and $\mathrm{H}_{2}$ Se. Several $\mathrm{Y}_{\mathrm{f}}$ s loaded with various metal chalcogenide QDs, such as PbSe, PbS, CdSe, CdS, ZnSe, ZnS, $\mathrm{Ag}_{2} \mathrm{Se}$, and $\mathrm{Ag}_{2} \mathrm{~S}$, were prepared from rigorously dried $\mathrm{M}^{+}$ $(\mathrm{M}=\mathrm{Ag})$ and $\mathrm{M}^{2+}(\mathrm{M}=\mathrm{Pb}, \mathrm{Cd}$, and $\mathrm{Zn})$-exchanged $\mathrm{Y}_{\mathrm{f}} \mathrm{s}$ treated with dry $\mathrm{H}_{2} \mathrm{~S}$ and $\mathrm{H}_{2} \mathrm{Se}$, respectively. All the numbers of generated MS and MSe units in $\mathrm{Y}_{\mathrm{f}}$ s were almost 32 per unit cell (the maximum amount for this zeolite is 32) as 
TABLE 1: Extonic Bohr radius (denoted as EBR), absorption coefficient $(\alpha)$, and 3rd-NLO responsibilities $(\beta$ and $\gamma)$ of [(MSe)]-Y $\mathrm{Y}_{\mathrm{f}}$ and [(MS)]$\mathrm{Y}_{\mathrm{f}}$.

\begin{tabular}{|c|c|c|c|c|c|c|c|}
\hline \multirow{2}{*}{ QDs } & \multirow{2}{*}{$\begin{array}{l}\text { EBR } \\
(\mathrm{nm})\end{array}$} & \multicolumn{3}{|c|}{$532 \mathrm{~nm}$} & \multicolumn{3}{|c|}{$1064 \mathrm{~nm}$} \\
\hline & & $\alpha^{[\mathrm{a}]}$ & $\beta^{[\mathrm{b}]}$ & $\gamma^{[c]}$ & $\alpha^{[\mathrm{a}]}$ & $\beta^{[\mathrm{b}]}$ & $\gamma^{[c]}$ \\
\hline $\mathrm{PbSe}$ & 72 & 18.12 & 6118 & -335 & 1.28 & 1550 & 147 \\
\hline $\mathrm{PbS}$ & 18 & 7.36 & 5680 & -284 & 0.60 & 1256 & -121 \\
\hline CdSe & 6 & 0.71 & 2822 & -179 & - & 653 & -47 \\
\hline $\mathrm{CdS}$ & 3 & - & 1206 & -68 & - & 525 & -35 \\
\hline $\mathrm{ZnSe}$ & 3.8 & - & 1050 & -50 & - & 596 & -40 \\
\hline $\mathrm{ZnS}$ & 2.5 & - & 708 & -37 & - & 325 & -16 \\
\hline AgSe & 2.9 & 5.37 & 4550 & -253 & 1.37 & 1024 & -93 \\
\hline $\mathrm{AgS}$ & 2.2 & 3.41 & 3880 & -227 & 1.41 & 910 & -80 \\
\hline
\end{tabular}

[a] In $\times 10^{3} \mathrm{~cm}^{-1}$. [b] In cm/GW. [c] In $\times 10^{-12} \mathrm{~cm}^{2} /$ W.

shown in SI Table 1 (in Supplementary Information available online at http://dx.doi.org/10.1155/2016/9519362). According to the previous report, most intercalated MS and MSe QDs require protection from moisture adsorption, which could be achieved by coating with octadecyltrimethoxysilane on the [(MS or MSe $)]-Y_{\mathrm{f}} \mathrm{S}$ surfaces [28].

The photographs of [(MS or MSe)]-Y $Y_{f}$ are shown in the right panel in Scheme 1. As is seen, the colour progressively changes from white to dark red, which could be attributed to the decrease in the band gap of loaded MS and MSe, respectively. The diffuse reflectance and absorption spectra of $[(\mathrm{MS}$ or $\mathrm{MSe})]-\mathrm{Y}_{\mathrm{f}} \mathrm{s}$ are shown in Figure 1, respectively. As is seen, the absorptions are distinctively blue shift when compared to those of bulk MS or MSe, which is due to the quantum size effects. The order of bulk band gap of each MS or MSe is as follows: $\mathrm{Ag}_{2} \mathrm{Se}(0.15 \mathrm{eV})<\mathrm{PbSe}(0.27 \mathrm{eV})$ $<\mathrm{PbS}(0.37 \mathrm{eV})<\mathrm{Ag}_{2} \mathrm{~S}(0.9 \mathrm{eV})<\mathrm{CdSe}(1.7 \mathrm{eV})<\mathrm{CdS}$ $(2.4 \mathrm{eV})<\mathrm{ZnSe}(2.6 \mathrm{eV})<\mathrm{CdS}(2.4 \mathrm{eV})<\mathrm{ZnS}(3.6 \mathrm{eV})$. Similarly, the order of optical band gap of [(MS or MSe)]$\mathrm{Y}_{\mathrm{f}} \mathrm{s}$ estimated from the absorption spectrum shown in SI2 in Supplementary Information indicated similar trend as follows: $\mathrm{Ag}_{2} \mathrm{Se}(0.15 \mathrm{eV})<\mathrm{PbSe}(0.27 \mathrm{eV})<\mathrm{PbS}(0.37 \mathrm{eV})$ $<\mathrm{Ag}_{2} \mathrm{~S}(0.9 \mathrm{eV})<\mathrm{CdSe}(1.7 \mathrm{eV})<\mathrm{CdS}(2.4 \mathrm{eV})<\mathrm{ZnSe}$ $(2.6 \mathrm{eV})<\mathrm{ZnS}(3.6 \mathrm{eV})$. Among the different QDs considered in this study, $\mathrm{PbSe}, \mathrm{PbS}, \mathrm{Ag}_{2} \mathrm{Se}, \mathrm{Ag}_{2} \mathrm{~S}$, and $\mathrm{CdSe}$ intercalated $\mathrm{Y}_{\mathrm{f}} \mathrm{s}$ with smaller band gap show strong absorption intensity at $532 \mathrm{~nm}$. This is called resonance. Particularly, the order of absorption intensity at $532 \mathrm{~nm}$, which is the nonlinear excitation wavelength, was $\mathrm{PbSe}<\mathrm{PbS}<\mathrm{Ag}_{2} \mathrm{Se}<\mathrm{Ag}_{2} \mathrm{~S}<$ $\mathrm{CdSe}$. On the other hand, $\mathrm{CdS}, \mathrm{ZnSe}$, and $\mathrm{ZnS}$ intercalated $\mathrm{Y}_{\mathrm{f}} \mathrm{s}$ present no absorption at $532 \mathrm{~nm}$, or, in other words, they were nonresonant. Furthermore, at the other nonlinear excitation wavelength of $1064 \mathrm{~nm}, \mathrm{PbSe}, \mathrm{PbS}, \mathrm{Ag}_{2} \mathrm{Se}$, and $\mathrm{Ag}_{2} \mathrm{~S}$ intercalated $\mathrm{Y}_{\mathrm{f}} \mathrm{s}$ show weak absorption. This implies that the wavelength $1064 \mathrm{~nm}$ is near-resonant. However, CdSe, ZnSe, $\mathrm{CdS}$, and $\mathrm{ZnS}$ show no absorption, which implies that these QDs are nonresonant at the wavelength of $1064 \mathrm{~nm}$. These three distinct wavelengths, namely, resonant, near-resonant, and nonresonant, depending on absorption spectrums, lead to huge differences in the $3 \mathrm{rd}-\mathrm{NLO}$ responses values.

The two 3rd-NLO responses, $\gamma$ (nonlinear refractive index) and $\beta$ (nonlinear absorption) coefficients at 532 and

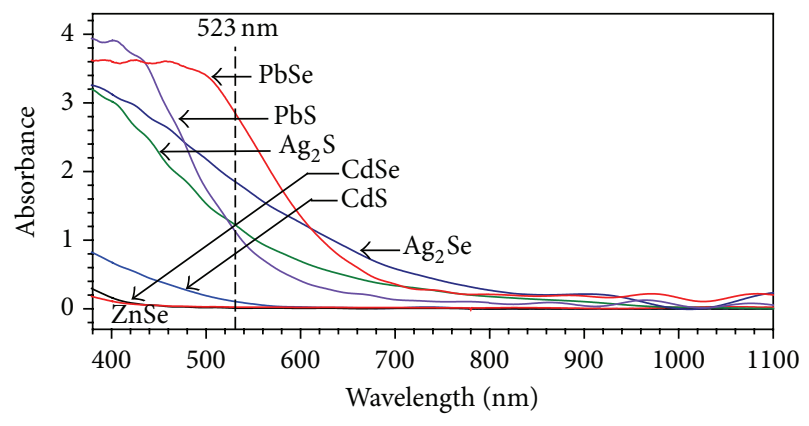

Figure 1: Absorption spectra of [MSe or MS]- $\mathrm{Y}_{\mathrm{f}} \mathrm{s}$ as indicated.

$1064 \mathrm{~nm}$, respectively, of [MS or $\mathrm{MSe}]-\mathrm{Y}_{\mathrm{f}}$ were obtained from the $z$-scan system as shown in Figure 2 using modelocked picosecond laser pulses with the pulse width of $50 \mathrm{ps}$. The validity of measurement system was confirmed by performing calibration measurement with $\mathrm{CS}_{2}$ liquid as wellknown standard material [26]. The nonlinear refractive index of $\mathrm{CS}_{2}$ was determined to be $3.5 \times 10^{6} \mathrm{~cm}^{2} / \mathrm{GW}$, which is in accordance with the standard value measured under similar conditions [26]. Besides, the $z$-scan was also conducted for the bare $\mathrm{Y}_{\mathrm{f}}$ without any QDs. No transmittance change was observed. This confirms that the 3rd-NLO effects originate from the intercalated QDs.

The measured values of nonlinear refractive coefficient, $\gamma$, and nonlinear absorption coefficient, $\beta$, of each of [MS or $\mathrm{MSe}]-\mathrm{Y}_{\mathrm{f}} \mathrm{S}$ at 532 and $1064 \mathrm{~nm}$ are listed in Table 1. The order of increase in the obtained $\gamma$ and $\beta$ values at $532 \mathrm{~nm}$ is as follows: $\mathrm{PbSe}\left(\gamma=-3.35 \times 10^{-10} \mathrm{~cm}^{2} / \mathrm{W} ; \beta=6118 \mathrm{~cm} / \mathrm{GW}\right)$ $<\operatorname{PbS}\left(\gamma=-2.84 \times 10^{-10} \mathrm{~cm}^{2} / \mathrm{W} ; \beta=5680 \mathrm{~cm} / \mathrm{GW}\right)<$ $\mathrm{Ag}_{2} \operatorname{Se}\left(\gamma=-2.53 \times 10^{-10} \mathrm{~cm}^{2} / \mathrm{W} ; \beta=4550 \mathrm{~cm} / \mathrm{GW}\right)<\mathrm{Ag}_{2} \mathrm{~S}$ $\left(\gamma=-2.27 \times 10^{-10} \mathrm{~cm}^{2} / \mathrm{W} ; \beta=3880 \mathrm{~cm} / \mathrm{GW}\right)<\mathrm{CdSe}(\gamma$ $\left.=-1.79 \times 10^{-10} \mathrm{~cm}^{2} / \mathrm{W} ; \beta=2822 \mathrm{~cm} / \mathrm{GW}\right)<\mathrm{ZnSe}(\gamma=$ $\left.-0.68 \times 10^{-10} \mathrm{~cm}^{2} / \mathrm{W} ; \beta=1206 \mathrm{~cm} / \mathrm{GW}\right)<\mathrm{CdS}(\gamma=-0.50$ $\left.\times 10^{-10} \mathrm{~cm}^{2} / \mathrm{W} ; \beta=1050 \mathrm{~cm} / \mathrm{GW}\right)<\mathrm{ZnS}(\gamma=-0.37 \times$ $\left.10^{-10} \mathrm{~cm}^{2} / \mathrm{W} ; \beta=708 \mathrm{~cm} / \mathrm{GW}\right)$. Depending on whether or not the QDs have linear absorption at $532 \mathrm{~nm}$ as nonlinear excitation wavelength, they can be divided into two distinct categories as follows: QDs having resonant nonlinearity, 


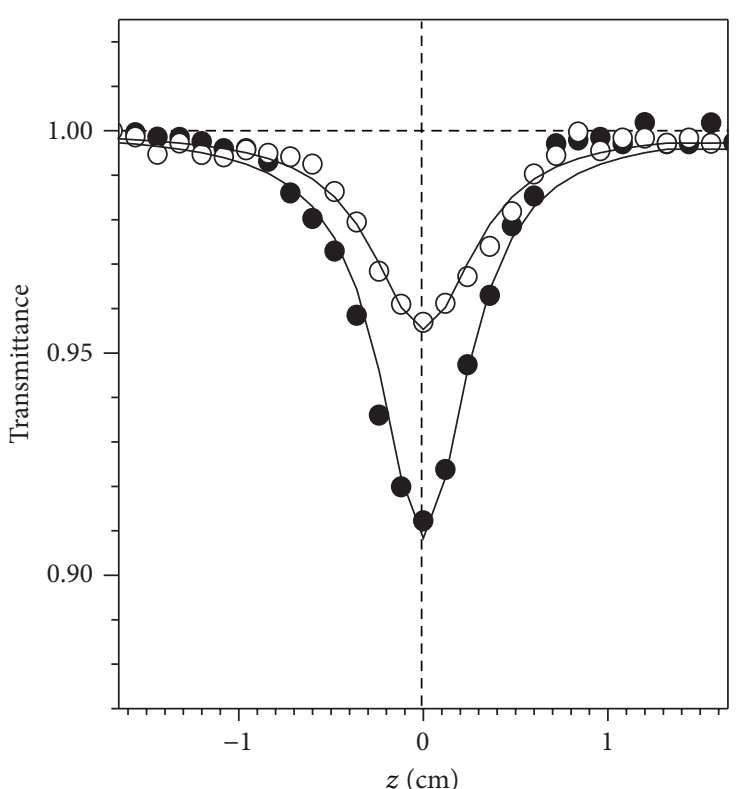

(a)

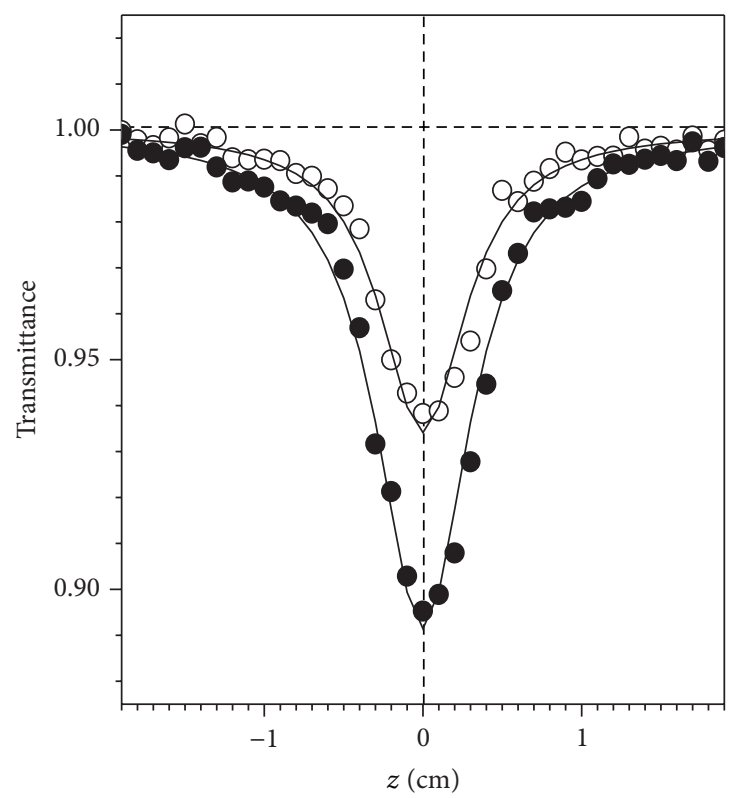

(c)

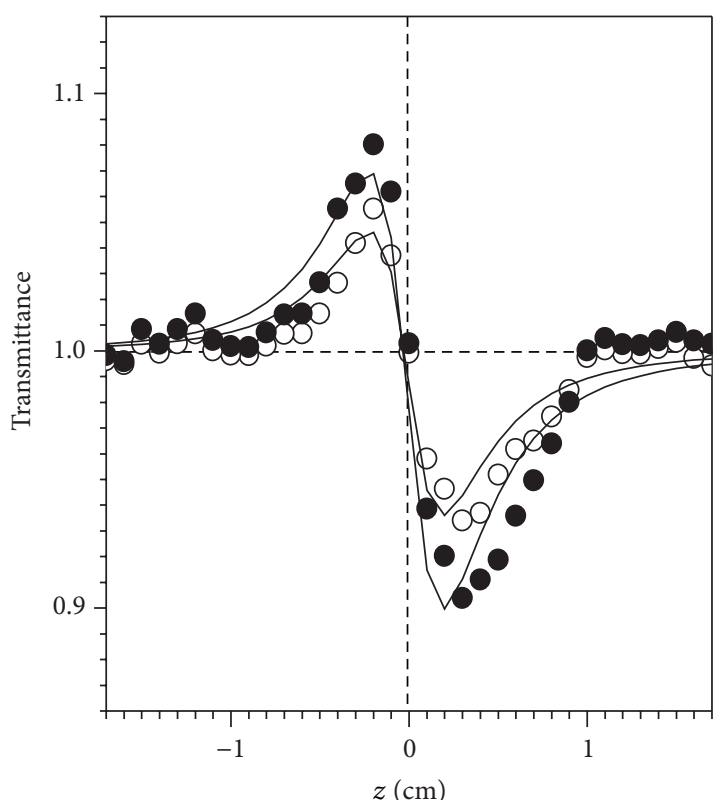

(b)

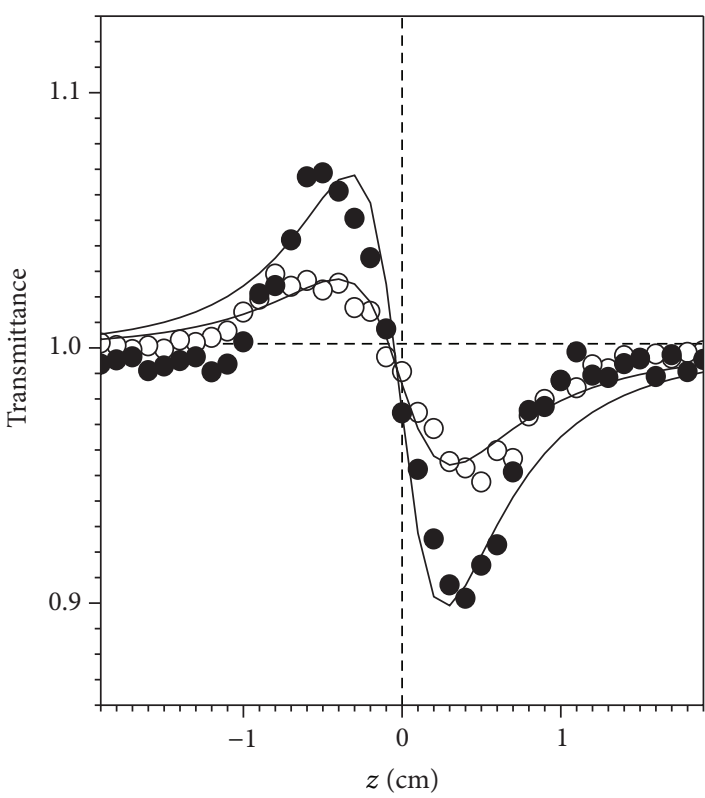

(d)

Figure 2: Measured $z$-scan data (symbols) and the theoretically fitted curves (solid curves) of [(PbSe)]-Y $\mathrm{Y}_{\mathrm{f}}$ obtained under the (a) closed- and (b) open-aperture conditions at $532 \mathrm{~nm}$ and under the (c) closed- and (d) open-aperture conditions at $1064 \mathrm{~nm}$. The input irradiance at the focal point $\left(I_{0}\right)$ was 0.10 and $0.18 \mathrm{GW} / \mathrm{cm}^{2}$ at $532 \mathrm{~nm}$ and 0.27 and $0.47 \mathrm{GW} / \mathrm{cm}^{2}$ at $1064 \mathrm{~nm}$.

such as $\mathrm{PbSe}, \mathrm{PbS}, \mathrm{Ag}_{2} \mathrm{Se}$, and $\mathrm{Ag}_{2} \mathrm{~S}$ and $\mathrm{CdSe}$, and those having nonresonant nonlinearity, such as $\mathrm{ZnSe}, \mathrm{CdS}$, and $\mathrm{ZnS}$ QDs. We plot the 3rd-NLO response, $\gamma$ and $\beta$ coefficients, against absorption coefficient at $532 \mathrm{~nm}$, as shown in Figure 3 . Interestingly, each $\gamma$ and $\beta$ value coincides with that of the absorption intensity of [MS or MSe]- $\mathrm{Y}_{\mathrm{f}} \mathrm{s}$ at $532 \mathrm{~nm}$. Besides, the 3rd-NLO activity values of QDs that exhibit absorption at $532 \mathrm{~nm}$ are larger than those of QDs that do not show absorption. This trend originates from the fact that the resonant excitation greatly enhances the 3rd-NLO response by giving rise to diverse processes, such as electronic polarization effect and nuclear and thermal processes, which may contribute to 3rd-NLO activity. We could confirm that the linear absorption intensity at the measured wavelength is predominantly affected by the resonant nonlinear optical properties. In addition, we could observe the relation between nonresonant 3rd-NLO response and exciton Bohr radius. This can be achieved by plotting the $\gamma$ and $\beta$ values against the exciton Bohr radius, respectively, in cases of $\mathrm{ZnSe}, \mathrm{CdS}$, and $\mathrm{ZnS}$ QDs in $\mathrm{Y}_{\mathrm{f}} \mathrm{s}$, which do not exhibit linear absorption 


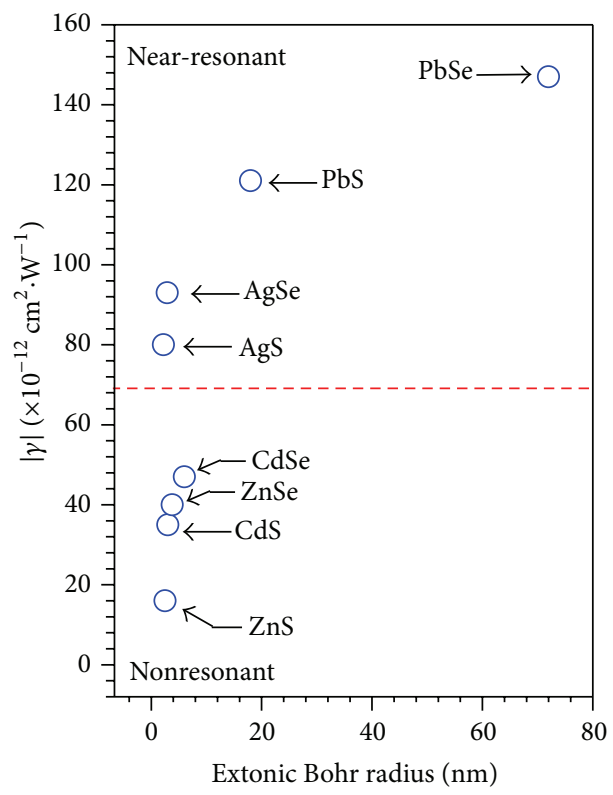

(a)

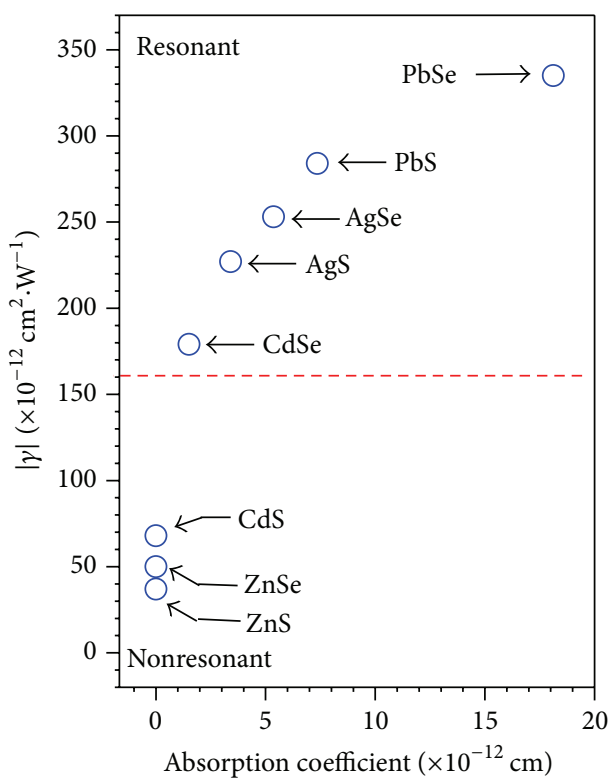

(c)

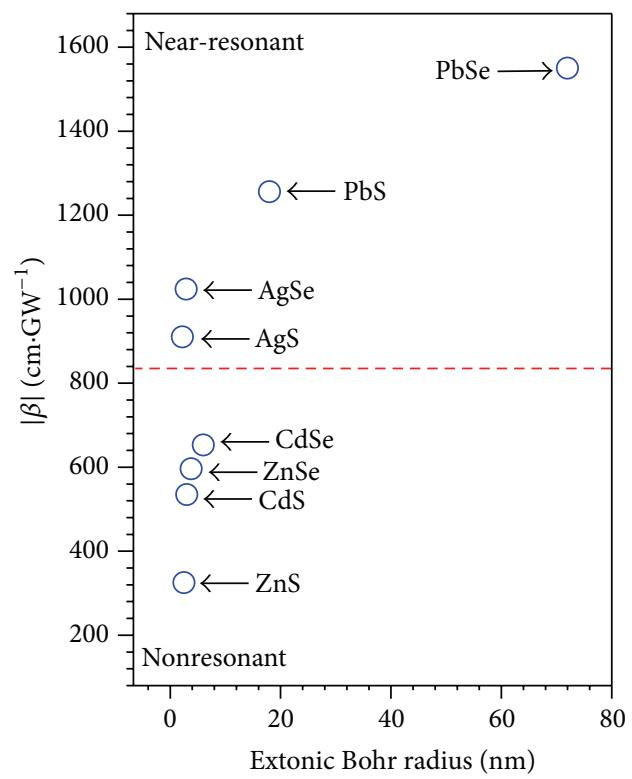

(b)

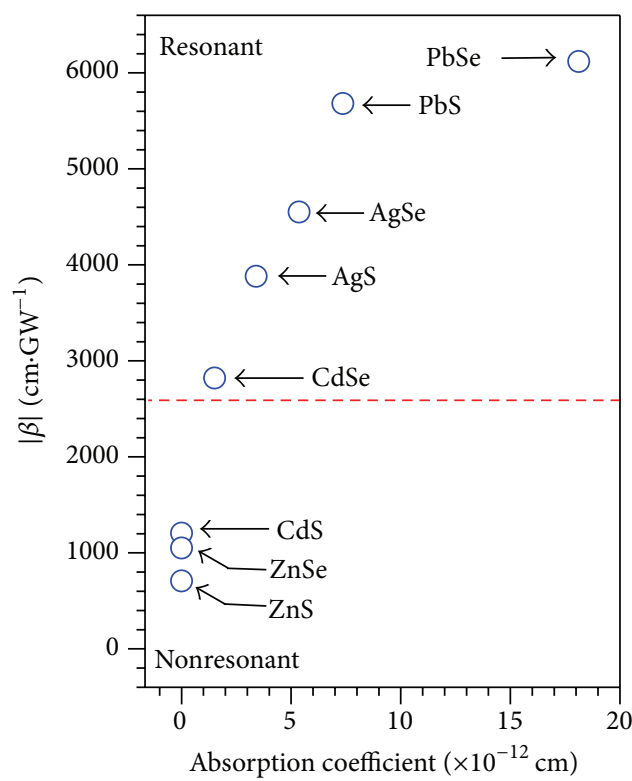

(d)

Figure 3: Plots of ((b) and (d)) $\beta$ and ((a) and (c)) $\gamma$ measured at ((a) and (b)) $1064 \mathrm{~nm}$ versus extonic Bohr radius and at ((c) and (d)) $532 \mathrm{~nm}$ versus absorption coefficient as indicated $[\mathrm{MSe}$ or $\mathrm{MS}]-\mathrm{Y}_{\mathrm{f}} \mathrm{s}$.

at $532 \mathrm{~nm}$. As shown in Figure 3, an increase in exciton Bohr radius results in an increase in nonresonant 3rd-NLO response.

On the other hand, the measured $\gamma$ and $\beta$ values at $1064 \mathrm{~nm}$ increase in the following order: $\operatorname{PbSe}(\gamma=-1.47 \times$ $\left.10^{-10} \mathrm{~cm}^{2} / \mathrm{W} ; \beta=1550 \mathrm{~cm} / \mathrm{GW}\right)<\operatorname{PbS}(\gamma=-1.21 \times$ $\left.10^{-10} \mathrm{~cm}^{2} / \mathrm{W} ; \beta=1256 \mathrm{~cm} / \mathrm{GW}\right)<\operatorname{Ag}_{2} \mathrm{Se}(\gamma=-0.93 \times$ $\left.10^{-10} \mathrm{~cm}^{2} / \mathrm{W} ; \beta=1024 \mathrm{~cm} / \mathrm{GW}\right)<\mathrm{Ag}_{2} \mathrm{~S}(\gamma=-0.80 \times$ $\left.10^{-10} \mathrm{~cm}^{2} / \mathrm{W} ; \beta=910 \mathrm{~cm} / \mathrm{GW}\right)<\operatorname{CdSe}(\gamma=-0.47 \times$ $\left.10^{-10} \mathrm{~cm}^{2} / \mathrm{W} ; \quad \beta=653 \mathrm{~cm} / \mathrm{GW}\right)<\mathrm{ZnSe}(\gamma=-0.4 \times$ $\left.10^{-10} \mathrm{~cm}^{2} / \mathrm{W} ; \quad \beta=596 \mathrm{~cm} / \mathrm{GW}\right)<\mathrm{CdS}(\gamma=-0.35 \times$ $\left.10^{-10} \mathrm{~cm}^{2} / \mathrm{W} ; \quad \beta=525 \mathrm{~cm} / \mathrm{GW}\right)<\mathrm{ZnS}(\gamma=-0.16 \times$ $\left.10^{-10} \mathrm{~cm}^{2} / \mathrm{W} ; \beta=325 \mathrm{~cm} / \mathrm{GW}\right)$, as summarized in Table 1 .

At the excitation wavelength corresponding to $1064 \mathrm{~nm}$, similar to $532 \mathrm{~nm}$, we could classify two distinct categories of QDs, namely, those having near-resonant nonlinearity, such as $\mathrm{PbSe}, \mathrm{PbS}, \mathrm{Ag}_{2} \mathrm{Se}$, and $\mathrm{Ag}_{2} \mathrm{~S}$, with absorption band edge near $1064 \mathrm{~nm}$, and those having nonresonant nonlinearity, such as CdSe, ZnSe, CdS, and ZnS QDs, with no absorption at $1064 \mathrm{~nm}$. Also, under the same conditions of excitation at $1064 \mathrm{~nm}$, the obtained near-resonant nonlinear coefficient values of $\beta$ and $\gamma$ from $\mathrm{PbSe}, \mathrm{PbS}, \mathrm{Ag}_{2} \mathrm{Se}$, and $\mathrm{Ag}_{2} \mathrm{~S}$ QDs 
in $\mathrm{Y}_{\mathrm{f}} \mathrm{s}$ are larger than the nonresonant nonlinear coefficient values of $\beta$ and $\gamma$ from CdSe, $\mathrm{ZnSe}, \mathrm{CdS}$, and $\mathrm{ZnS}$ QDs in $\mathrm{Y}_{\mathrm{f}} \mathrm{s}$. This could be explained on the basis of the abovementioned reasons from the case of $532 \mathrm{~nm}$.

Furthermore, the effect of exciton Bohr radius on the 3rdNLO activities of the intercalated QDs was observed by plotting the $\beta$ and $\gamma$ values against the exciton Bohr radius in both cases of near-resonant and nonresonant nonlinearity under $1064 \mathrm{~nm}$ excitation (SI-3 in Supplementary Information). These plots depict a remarkably good correlation between the 3rd-NLO activities and the exciton Bohr radius. These results confirm that the 3rd-NLO activities increase with the exciton Bohr radius in case of near-resonant or nonresonant nonlinearity.

Among the various intercalated QDs prepared and analysed in this study, we could observe remarkably high 3rdNLO activities in zeolite-intercalated PbSe QDs. In particular, $\mathrm{PbSe}$ is expected to be an attractive material for 3rd-NLO among the other semiconductor QDs due to the larger quantum confinement effect than $\mathrm{PbS}$ and other semiconductors. Actually, the highest values of nonlinear refraction $(\gamma)$ and absorption $(\beta)$ coefficients measured from the PbSe sample were $-1.35 \times 10^{-10} \mathrm{~cm}^{2} / \mathrm{W}$ and $2118 \mathrm{~cm} / \mathrm{GW}$ at $532 \mathrm{~nm}$ and $1.47 \times 10^{-10} \mathrm{~cm}^{2} / \mathrm{W}$ and $1550 \mathrm{~cm} / \mathrm{GW}$ at $1064 \mathrm{~nm}$, respectively. In particular, the magnitude of the absorption coefficient $\beta$ of $[\mathrm{PbSe}]-\mathrm{Y}_{\mathrm{f}}$ at $1064 \mathrm{~nm}$ is as large as $\sim 7$ times higher than the highest magnitude ever obtained. Furthermore, the $\gamma$ and $\beta$ values of $[\mathrm{PbSe}]-\mathrm{Y}_{\mathrm{f}}$ at $532 \mathrm{~nm}$ and $1064 \mathrm{~nm}$ represent the values first ever measured from any $\mathrm{PbSe} \mathrm{QD} /$ matrix composites. We observed that the significant increase in cation size, as we go from $\mathrm{H}^{+}$to $\mathrm{Rb}^{+}$, is the key factor underlying the remarkably high 3rd-NLO responses of the $\mathrm{PbSe}$ QDs, which is in accordance with previous reports (SI-4 in Supplementary Information). The highest values of nonlinear refraction $(\gamma)$ and absorption $(\beta)$ coefficients measured from the above samples were $-7.95 \times 10^{-10} \mathrm{~cm}^{2} / \mathrm{W}$ and $9118 \mathrm{~cm} / \mathrm{GW}$ at $532 \mathrm{~nm}$ and $9.52 \times 10^{-10} \mathrm{~cm}^{2} / \mathrm{W}$ and $6550 \mathrm{~cm} / \mathrm{GW}$ at $1064 \mathrm{~nm}$, respectively, after ion exchanged with $\mathrm{Rb}^{+}$(SI-4 in Supplementary Information). To the best of our knowledge, this is the highest value that has ever been reported in zeolite QD composite and QDs in other matrices.

\section{Conclusion}

In summary, we intercalated various metal chalcogenide QDs, such as PbSe, PbS, CdSe, CdS, $\mathrm{ZnSe}, \mathrm{ZnS}, \mathrm{Ag}_{2} \mathrm{Se}$, and $\mathrm{Ag}_{2} \mathrm{~S}$, into transparent zeolite films and compared their 3rdNLO responses at different wavelengths, namely, $532 \mathrm{~nm}$ and $1065 \mathrm{~nm}$. Results indicated that the zeolite provides an ideal platform for the tuneable 3rd-NLO QDs materials with high sensitivities, as evidenced from the 3rd-NLO responses of the intercalated QDs in zeolite. In addition, results suggest that the 3rd-NLO responses are greatly affected by not only the absorption intensity at the excited wavelength but also the exciton Bohr radius.

\section{Competing Interests}

The author declares that they have no competing interests.

\section{References}

[1] M. Mass, J. M. Enoch, E. W. Van Stryland, and W. L. Wolfe, Handbooks of Optics IV, Fiber Optics \& Nonlinear Optics, Mcgraw-Hill, New York, NY, USA, 2nd edition, 2001.

[2] M. R. Shcherbakov, P. P. Vabishchevich, A. S. Shorokhov et al., "Ultrafast all-optical switching with magnetic resonances in nonlinear dielectric nanostructures," Nano Lett, vol. 15, no. 10, pp. 6985-6990, 2003.

[3] C. Monat, C. Grillet, M. Collins et al., "Integrated optical autocorrelator based on third-harmonic generation in a silicon photonic crystal waveguide," Nature Communications, vol. 5, article 3246, 2014.

[4] Q. Bao, J. Chen, Y. Xiang et al., "Graphene nanobubbles: a new optical nonlinear material," Advanced Optical Materials, vol. 3, no. 6, pp. 744-749, 2015.

[5] P. Sudheesh, N. K. Siji Narendran, and K. Chandrasekharan, "Third-order nonlinear optical responses in derivatives of phenylhydrazone by Z-scan and optical limiting studiesinfluence of noble metal nanoparticles," Optical Materials, vol. 36, no. 2, pp. 304-309, 2013.

[6] Y. Mi, P. Liang, Z. Yang et al., "Nonlinear optical beam propagation for optical limiting," Applied Optics, vol. 38, no. 24, pp. 5168-5180, 1999.

[7] S. Kahmann, A. Mura, L. Protesescu, M. V. Kovalenko, C. J. Brabec, and M. A. Loi, "Opto-electronics of PbS quantum dot and narrow bandgap polymer blends," Journal of Materials Chemistry C, vol. 3, no. 21, pp. 5499-5505, 2015.

[8] G. H. Carey, L. Levina, R. Comin, O. Voznyy, and E. H. Sargent, "Record charge carrier diffusion length in colloidal quantum dot solids via mutual dot-to-dot surface passivation," Advanced Materials, vol. 27, no. 21, pp. 3325-3330, 2015.

[9] J. Aguilera-Sigalat and D. Bradshaw, "Synthesis and applications of metal-organic framework-quantum dot (QD@MOF) composites," Coordination Chemistry Reviews, vol. 307, part 2, pp. 267-291, 2016.

[10] S. Saha, G. Das, J. Thote, and R. Banerjee, "Photocatalytic metalorganic framework from CdS quantum dot incubated luminescent metallohydrogel," Journal of the American Chemical Society, vol. 136, no. 42, pp. 14845-14851, 2014.

[11] H. Cheng, Y. Wang, H. Dai, J. Han, and X. Li, "Nonlinear optical properties of $\mathrm{PbS}$ colloidal quantum dots fabricated via solvothermal method," The Journal of Physical Chemistry C, vol. 119, no. 6, pp. 3288-3292, 2015.

[12] I. Gdor, A. Shapiro, C. Yang, D. Yanover, E. Lifshitz, and S. Ruhman, "Three-pulse femtosecond spectroscopy of PbSe nanocrystals: $1 \mathrm{~S}$ bleach nonlinearity and sub-band-edge excited-state absorption assignment," ACS Nano, vol. 9, no. 2, pp. 2138-2147, 2015.

[13] H. Zeng, J. Han, D. Qian, and Y. Gu, “Third-order nonlinear optical properties of multiwalled carbon nanotubes modified by CdS nanoparticles," Optik, vol. 125, no. 21, pp. 6558-6561, 2014.

[14] M. Nyk, D. Wawrzynczyk, J. Szeremeta, and M. Samoc, "Spectrally resolved size-dependent third-order nonlinear optical properties of colloidal CdSe quantum dots," Applied Physics Letters, vol. 100, no. 4, Article ID 041102, 2012.

[15] A. Rakovich, I. Nabiev, A. Sukhanova et al., "Large enhancement of nonlinear optical response in a hybrid nanobiomaterial consisting of bacteriorhodopsin and cadmium telluride quantum dots," ACS Nano, vol. 7, no. 3, pp. 2154-2160, 2013.

[16] Y. Wang, X. Yang, T. C. He et al., "Near resonant and nonresonant third-order optical nonlinearities of colloidal InP/ZnS 
quantum dots," Applied Physics Letters, vol. 102, Article ID 021917, 2013.

[17] Z. Huang, M. Li, D. Jia et al., "A facile approach to heteronanorods of $\mathrm{Ag}_{2} \mathrm{Se}-\mathrm{MSe}(\mathrm{M}=\mathrm{Cd}, \mathrm{Zn})$ with enhanced thirdorder optical nonlinearity," Journal of Materials Chemistry C, vol. 2, no. 8, pp. 1418-1426, 2014.

[18] X. Du, L. Zhang, G. Dong et al., "Coloration and nonlinear optical properties of $\mathrm{ZnTe}$ quantum dots in $\mathrm{ZnO}-\mathrm{TeO}_{2}-\mathrm{P}_{2} \mathrm{O}_{5}$ glasses," Journal of the American Ceramic Society, vol. 97, no. 1, pp. 185-188, 2014.

[19] W. Xiang, H. Zhao, J. Zhong et al., "Synthesis and third-order optical nonlinearities of $\operatorname{In}_{2} \mathrm{~S}_{3}$ quantum dots glass," Journal of Alloys and Compounds, vol. 553, pp. 135-141, 2013.

[20] W. Xiang, H. Zhao, J. Zhong et al., "Preparation and the thirdorder optical nonlinearities of the sodium borosilicate glass doped with Cu 7.2S 4 quantum dots," Journal of Non-Crystalline Solids, vol. 358, no. 18-19, pp. 2641-2649, 2012.

[21] W. Xiang, H. Zhao, J. Zhong et al., "The preparation and the third-order optical nonlinearities of sodium borosilicate glass doped with CuInS 2 quantum dots," Journal of the American Ceramic Society, vol. 95, no. 5, pp. 1588-1594, 2012.

[22] B. Cichy, D. Wawrzynczyk, A. Bednarkiewicz, M. Samoc, and W. Strek, "Third-order nonlinear optical response of $\mathrm{CuInS}_{2}$ quantum dots-bright probes for near-infrared biodetection," Applied Physics Letters, vol. 102, no. 24, Article ID 243702, 2013.

[23] Y. Wang, "Nonlinear optical properties of nanometer-sized semiconductor clusters," Accounts of Chemical Research, vol. 24, no. 5, pp. 133-139, 1991.

[24] G. D. Stucky and J. E. Mac Dougall, "Quantum confinement and host/guest chemistry: probing a new dimension," Science, vol. 247, no. 4943, pp. 669-678, 1990.

[25] H. S. Kim and K. B. Yoon, "Preparation and characterization of $\mathrm{CdS}$ and $\mathrm{PbS}$ quantum dots in zeolite $\mathrm{Y}$ and their applications for nonlinear optical materials and solar cell," Coordination Chemistry Reviews, vol. 263-264, pp. 239-256, 2014.

[26] H. S. Kim and K. B. Yoon, "Increase of third-order nonlinear optical activity of $\mathrm{PbS}$ quantum dots in zeolite $\mathrm{Y}$ by increasing cation size," Journal of the American Chemical Society, vol. 134, no. 5, pp. 2539-2542, 2012.

[27] H. Lee and H. S. Kim, "Work-function engineering in lead sulfide and cadmium sulfide quantum dots incorporated into zeolite Y using ion exchange," Particle \& Particle Systems Characterization, vol. 33, no. 3, pp. 126-131, 2016.

[28] N. C. Jeong, H. S. Kim, and K. B. Yoon, "Tight confinement of semiconductor quantum dots within zeolite by surface silylation," Langmuir, vol. 21, no. 13, pp. 6038-6047, 2005. 

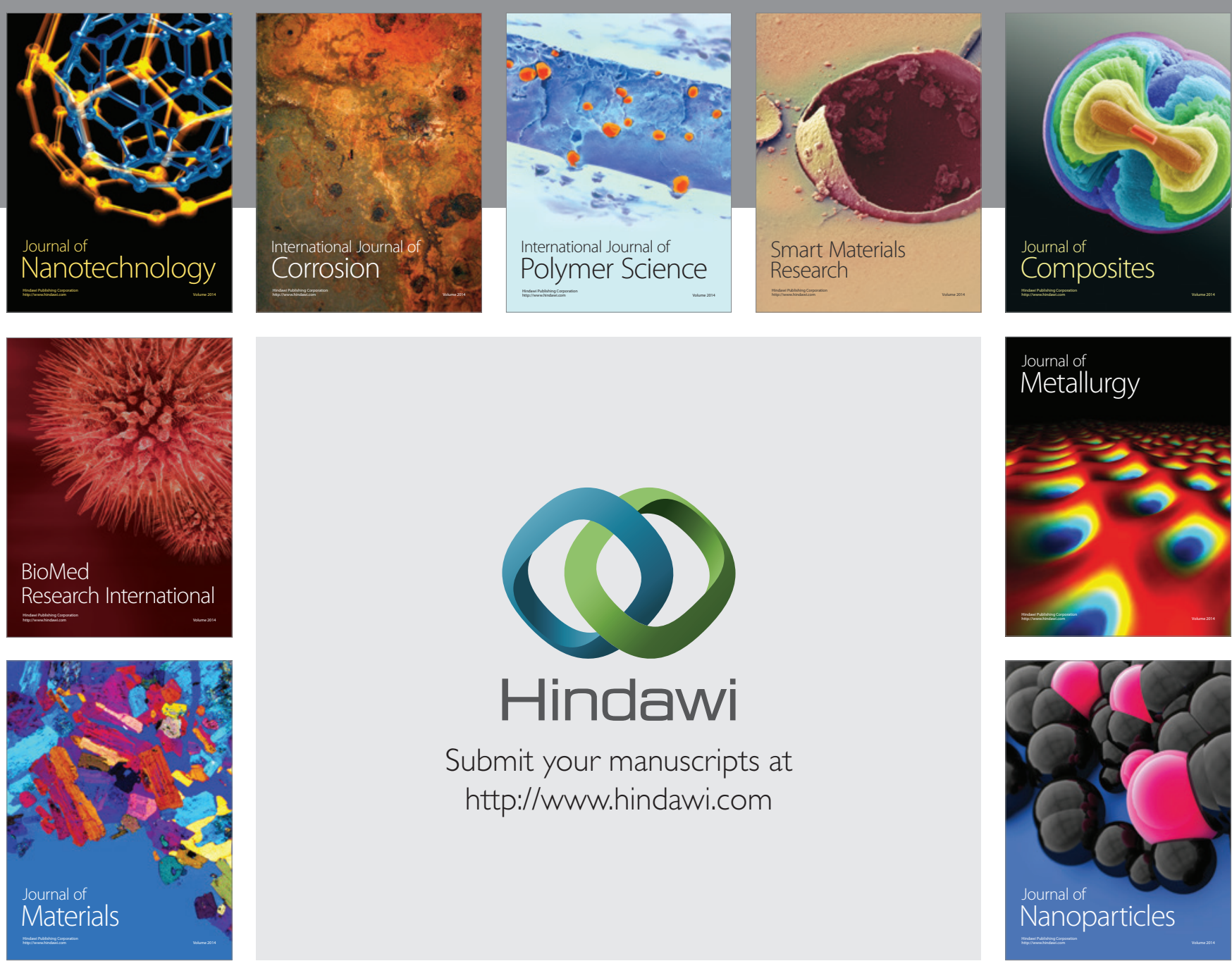

\section{Hindawi}

Submit your manuscripts at

http://www.hindawi.com

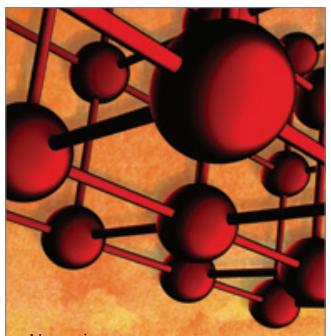

Materials Science and Engineering
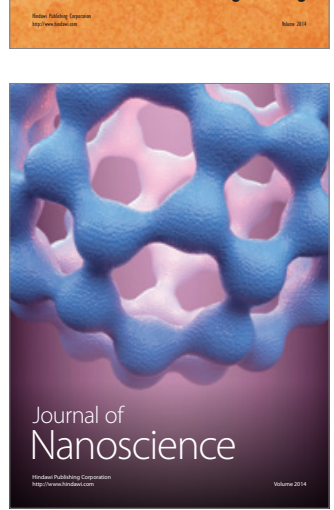
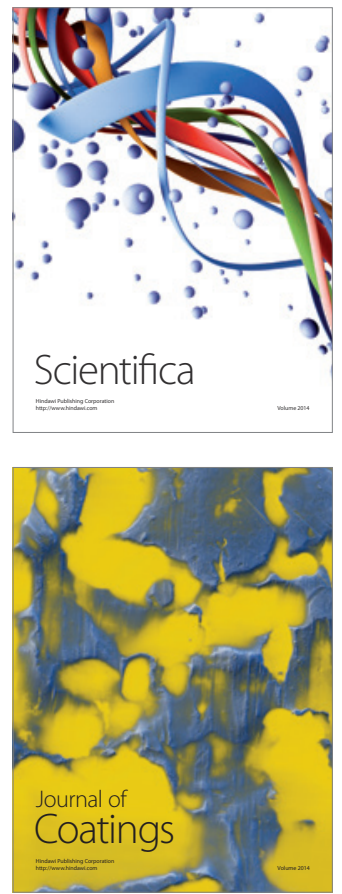
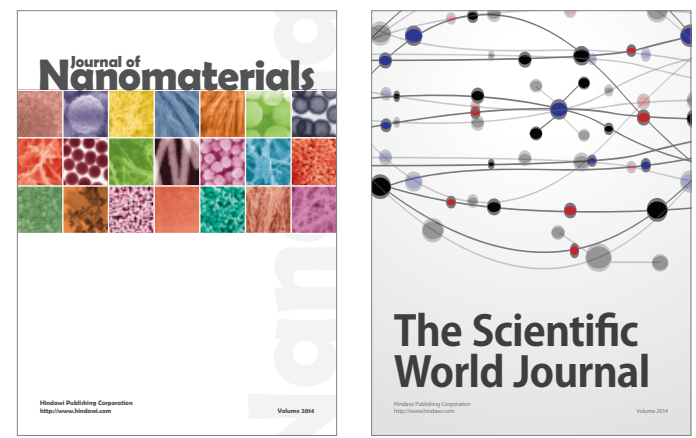

The Scientific World Journal
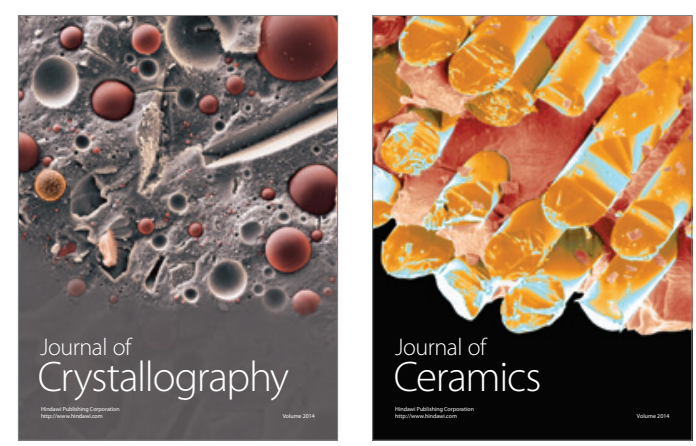
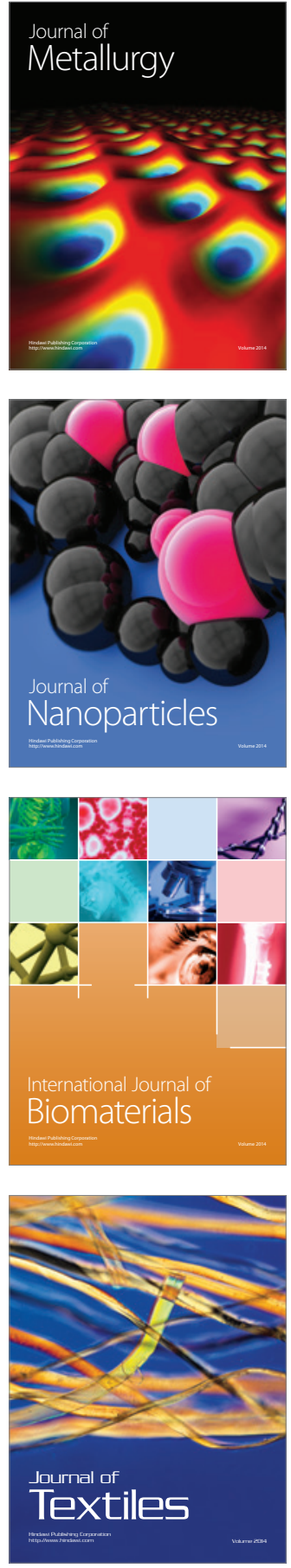